\title{
População infantil e adolescente nas ruas Principais temas de pesquisa no Brasil
}

\section{Children and adolescents on the streets}

Main research themes in Brazil

\author{
Población infantil y adolescente en las calles \\ Principales temas de investigación en Brasil
}

\author{
(1) Irene Rizzini ${ }^{1}$ \\ Renata Mena Brasil do Couto ${ }^{1}$
}

\begin{abstract}
Resumo: Crianças e adolescentes em situação de rua tornaram-se um fenômeno comum para aqueles que circulam pelas áreas centrais das grandes cidades brasileiras. Embora essa seja uma questão social complexa, ela ainda é marcada pela invisibilidade na agenda política nacional. Este artigo visa contribuir para o aprofundamento do debate contemporâneo sobre o tema, analisando-o em suas múltiplas dimensões, a partir do levantamento da produção acadêmica nacional sobre população infantil e adolescente em situação de rua, publicada entre 2000 e 2015. As autoras destacam importantes aspectos abordados por pesquisadores de todo o país, muitos dos quais questionam as tipificações e as crenças que homogeneizavam este grupo, contribuindo para a compreensão dos aspectos culturais e históricos que caracterizam esses sujeitos. Estes estudos abordam, ainda, a importância fundamental das políticas públicas, assinalando que, embora a responsabilidade do estado sobre esta população esteja prevista em uma série de instrumentos legais e planos governamentais, os direitos de crianças e adolescentes em situação de rua ainda carecem de priorização, efetivação e monitoramento para que façam alguma diferença em suas vidas.
\end{abstract}

Palavras-chave: Crianças e adolescentes; Situação de rua; Pesquisas brasileiras.

Abstract: Children and adolescents in the situation of the streets are a common sight for people who walk in the centers of large Brazilian cities. Although these young people represent a complex social problem, it is a problem marked by its absence on the national political agenda. This article seeks to enlarge the debate on the topic analyzing its multiple dimensions by examining this topic in the national academic literature between 2000 and 2015. In this analysis the authors note that the majority of studies raise the issue that the categorizations and beliefs regarding street children are commonly portrayed as if they were a homogeneous group. In this way the studies

\footnotetext{
${ }^{1}$ Pontifícia Universidade Católica do Rio de Janeiro (Puc-Rio, Rio de Janeiro, RJ, Brasil). autoras.dados_biográficos
} 
contribute to a cultural and historical understanding of the young people. These studies also address the fundamental importance of public policies, emphasizing that although the public responsibility for this population is set out in a series of legal instruments and government plans, the rights of children and adolescents in the situation of the streets still lack necessary effectiveness and monitoring in order to make a real difference in their lives.

Keywords: Children and adolescents; Street situation; Brazilian research.

Resumen: Niños y adolescentes en situación de calle se han convertido en un fenómeno común para aquellos que circulan por las áreas centrales de las grandes ciudades brasileñas. Si bien este fenómeno representa una cuestión social compleja, aún está marcado por la invisibilidad en la agenda política nacional. Este artículo está dirigido a profundizar en el debate contemporáneo sobre esta cuestión, analizándolo en sus múltiples dimensiones a partir del estudio de la producción académica nacional, publicada entre los años 2000 y 2005. Las autoras resaltan importantes discusiones con aportes de investigadores de todo el país. La mayor parte de ellos cuestiona las tipificaciones y las creencias que homogeneizaban a este grupo, contribuyendo así a la comprensión de los aspectos culturales e históricos que caracterizan a estos sujetos. Los estudios, además, abordan la importancia fundamental de las políticas públicas, señalando que, aún cuando la responsabilidad del estado sobre esta población esté prevista en instrumentos legales y planos gubernamentales, los derechos de niños y adolescentes en situación de calle todavía carecen de prioridad, efectividad y seguimiento para que hagan diferencia en sus vidas.

Palabras clave: Niños y adolescentes; Situación de calle; Investigaciones brasileñas.

\section{Introdução}

Crianças e adolescentes em situação de rua tornaram-se um fenômeno comum para aqueles que circulam pelas áreas centrais das grandes cidades brasileiras. Por muito tempo eles foram chamados de "meninos de rua" e foram caracterizados apenas como um problema social. Foi nos anos 1980 que este termo se popularizou no Brasil fazendo referência a um grupo social que ganhava visibilidade nas grandes metrópoles dos países latino-americanos. Todavia, desde então, diferentes estudos foram realizados sobre esta população e este interesse provocou mudanças, tanto na compreensão do fenômeno, como em sua nomenclatura.

A visão de que essas crianças e esses adolescentes eram um problema em si foi sendo paulatinamente substituída conforme se compreendiam as origens e os fatores responsáveis por sua ida para as ruas. O entendimento acerca da heterogeneidade deste grupo e do fato de que a rua não deveria ser considerada como definidora de suas vidas trouxe questionamentos relacionados à formação de suas identidades e subjetividades. Assim, para enfatizar a transitoriedade e 
efemeridade das condições de vida e do perfil desta população, o termo "em situação de rua" foi ganhando espaço no debate.

Essa e outras terminologias que imprimem entendimentos semelhantes, como "em condição de rua" e "que vivem nas ruas", se referem a indivíduos que, embora mantenham algum vínculo familiar e/ou um endereço, passam a maior parte do seu tempo diário nas ruas, desacompanhados de um adulto responsável, tendo este espaço como uma referência, seja para moradia ou para trabalho. A ida desses meninos e meninas para as ruas frequentemente representa um sinal extremo e um pedido de socorro, que antes não foi ouvido ou efetivamente reconhecido. No geral, crianças e adolescentes em situação de rua se sentem invisíveis dentro de suas famílias e comunidades. No entanto, nas ruas, o enfraquecimento desses vínculos, assim como a proteção inadequada do estado, a ausência da escola, o trabalho infantil, o envolvimento com o tráfico de drogas, a exploração sexual e a violência tornam esses sujeitos um grupo particularmente suscetível à violação de direitos.

Uma questão social complexa e delicada como esta demanda serviços, programas e ações eficazes. No entanto, ainda existe uma grande invisibilidade política relacionada a este segmento, ou seja, embora a responsabilidade do estado sobre esta população esteja prevista em uma série de instrumentos legais e planos governamentais, os direitos de crianças e adolescentes em situação de rua ainda carecem de aprimoramento, efetivação e monitoramento. É neste sentido que este artigo visa contribuir para o aprofundamento do debate contemporâneo. Nosso objetivo é analisar as múltiplas dimensões do fenômeno, construindo não só um guia para aqueles interessados em explorar a literatura recente que versa sobre este tema, mas também ofertando subsídios para pesquisas e políticas públicas que possam resultar em prioridades de ação que façam diferença na vida dos meninos e meninas que vivem nas ruas.

Para isso, apresentamos uma síntese dos principais temas abordados na produção acadêmica nacional, publicada entre 2000 e 2015, sobre crianças e adolescentes em situação de rua. ${ }^{1}$ Ao longo do levantamento que subsidiou este trabalho, foram encontrados mais de 800 títulos relacionados ao tema e que atendiam aos padrões estabelecidos pela pesquisa. Após a finalização da triagem e quantificação dos textos publicados, realizamos a leitura do material que se encontrava disponível na íntegra para download e o catalogamos por meio de fichas, que contêm informações como referência bibliográfica, resumo

\footnotetext{
${ }^{1}$ Este artigo teve como base uma pesquisa realizada no âmbito do projeto "Políticas públicas e os desafios da implementação: análise do caso da política de atendimento a crianças e adolescentes em situação de rua no Rio de Janeiro", com apoio da Faperj (CNE, Cientista do nosso estado, 2014-2017; Faperj Ref. N. E-26/201.274/2014).
} 
e palavras-chave. Neste artigo, incluiremos apenas os debates daqueles textos em que os autores afirmam seu foco sobre crianças e adolescentes em situação de rua, destacando aspectos sobre suas vidas neste contexto. Esta análise tem como base 116 artigos, teses e dissertações que compõem as seções temáticas apresentadas ao longo deste trabalho.

\section{Caracterizando a vida nas ruas}

Uma grande variedade de estudos mostra que a transitoriedade da vida nas ruas impossibilita que seja traçado um perfil único desses sujeitos. No geral, os textos analisados apenas retratam os atributos dos sujeitos em um período delimitado de tempo e em um ambiente específico. A diversidade da rua enquanto ambiente de desenvolvimento; a relação com a família e a escola; o cotidiano e as atividades desempenhadas; o tempo de permanência na rua; e as redes construídas neste espaço e fora dele fazem parte do universo de elementos a serem considerados na construção de interpretações que respeitem a heterogeneidade desses sujeitos (Alves et al., 2002; Martins, 2002).

Parece haver uma distinção entre aqueles que consideram o ambiente da rua como definitivo nas condições de vida, nas formas de existência, nas práticas sociais e na identidade dos jovens em situação de rua (Matias, 2011); e aqueles que buscam desmistificar a ideia de uma "cultura de rua", considerando que os sujeitos que ali habitam reproduzem os valores sociais dominantes (Leal, 2007). Neste segundo caso, compreende-se que, ao se pensar os sujeitos a partir da rua, constroem-se classificações, estereótipos e programas que geram uma identidade homogênea para experiências heterogêneas e fragmentadas.

Mesmo diante de condições de vida precárias e das violações de direitos sofridas, a solidariedade e a valorização da família, da educação e do trabalho seguem presentes no cotidiano destes sujeitos. Eles parecem ser capazes de visualizar perspectivas futuras para além da rua e de construir formas de se relacionar com o mundo que não sejam perpassadas exclusivamente pelo abandono e pela violência (Estivalet, 2010). Entretanto, aqueles que se envolvem com grupos na rua parecem ter mais dificuldade de romper com esse universo (Sobral, 2008).

De acordo com a literatura analisada, existem diferentes olhares sobre a experiência de vida nas ruas. É possível destacar aspectos positivos, relacionados ao acolhimento, a fonte de trabalho e lazer, a liberdade e a tentativa de superação de condições adversas; e aspectos negativos, associados à estigmatização e à marginalização. Representações ambíguas como estas nos permitem questionar a ideia de que crianças e adolescentes estão nas ruas 
apenas por vontade ou desejo, uma vez que enfrentam episódios frequentes de violência e criminalidade (Arpini; Quintana; Gonçalves, 2010; Nóbrega e Lucena, 2004).

\section{Afastamento de casa}

Compreender o contexto econômico, social, político e cultural no qual se inserem crianças e adolescentes é fundamental para o debate acerca dos motivos que as impulsionam para as ruas. Há uma ampla gama de fatores relacionados a essa questão, no entanto, estudos apontam que condições socioeconômicas precárias podem acarretar problemas de natureza psicossocial, afetando a saúde física e mental dos indivíduos. Esses fatores podem gerar, inclusive, o afastamento de crianças e adolescentes de sua família e de sua comunidade, como já apontava Winnicott (1996) décadas atrás. Infelizmente, a pobreza urbana e os fatores a ela associados, como a violência, os abusos e a negligência, inclusive no contexto familiar, permanecem sendo as principais causas do afastamento de crianças e adolescentes de suas casas.

Alguns fatores como a "ausência da mãe", a "agressões dos genitores" e a "miséria e desagregação familiar" fazem parte das múltiplas dificuldades encontradas na estrutura familiar desses sujeitos, que veem na rua uma alternativa para o tratamento austero, negligente e/ou agressivo de seus responsáveis (Ribeiro, 2001). A violência aparece em destaque nos relatos das crianças e adolescentes pesquisadas como justificativa para o abandono do lar. Discussões, brigas constantes em casa, maus tratos e abusos físicos figuram no rol das violências vivenciadas em ambiente familiar (Yunes et al., 2001; Moura; Silva; Noto, 2009).

A busca por maior liberdade também emerge como um elemento que impulsiona à ida para as ruas, provocando certo "deslumbramento", uma vez que ali tudo parece ser permitido (Cirino; Alberto, 2009). Todavia, é importante destacar o fato de que parte das crianças e adolescentes chega às ruas em busca de trabalho para ajudar no sustento de suas famílias ou mesmo para conseguir dinheiro para seus gastos pessoais (Paludo; Koller, 2008).

Questões financeiras e afetivas podem provocar e agravar os processos de enfraquecimento dos laços afetivos e comunitários e, assim, influenciar definitivamente na dinâmica e nas configurações das famílias, tornando-se as principais causas da ida de crianças e adolescentes para as ruas (Silva; Avelar, 2014). Em geral, o afastamento do lar pode se consolidar diante do fortalecimento de alternativas de afeto e solidariedade oferecidas nas ruas e da construção de fortes redes de relacionamento, positivas ou negativas, com os amigos, as drogas e as instituições de assistência e acolhimento. Uma relação 
complexa de fatores gera processos graduais de afastamento, fragilização e rompimento dos vínculos familiares e comunitários. Nestas circunstâncias, a circulação, o ir e vir entre a casa, a rua e as instituições de acolhimento, constitui uma das principais características da vida de crianças e adolescentes em situação de rua (Rizzini; Neumann; Cisneros, 2009).

\section{Família}

Embora as relações familiares de crianças e adolescentes em situação de rua sejam permeadas por conflitos, vulnerabilidades e dificuldades, inclusive no campo psicossocial e afetivo, a família permanece sendo uma importante rede de pertencimento para esses sujeitos. Seus vínculos resistem, ainda que fragmentados e permeados por ambivalências.

Nas pesquisas analisadas, as famílias de origem de crianças e adolescentes em situação de rua são, com frequência, numerosas, marcadas pela violência, pela carência material e afetiva, por ameaças na comunidade, pela perda de parentes, pelo uso de drogas e pelo trabalho infantil. O modelo familiar mais comum não é o nuclear e os rearranjos familiares, que incluem recasamentos e separações, são descritos com naturalidade. Ainda assim, os grupos familiares costumam girar em torno das mães. Os pais biológicos geralmente estão ausentes e, em algumas casas, a figura do padrasto acaba complicando as relações intrafamiliares. Histórias de abuso físico e sexual são uma constante nos relatos destas crianças e destes adolescentes (Paludo; Koller, 2008; Arpini; Quintana; Gonçalves, 2010).

Em parte dos casos, a casa representa privação e o desenvolvimento forçado de relações intrafamiliares problemáticas. Afeto e aceitação, alternados com indicações de maus-tratos e rejeição, fazem parte do cotidiano familiar desses sujeitos. Essa dinâmica costuma gerar uma ambivalência afetiva em relação ao lar e certa fragilidade nos laços familiares (Silva; Avelar, 2014). Nas ruas, parte das crianças e adolescentes segue idealizando suas famílias de origem e afirma desejar retornar para suas casas (Ferreira; Littig; Vescovi, 2014). Episódios que revelam a ausência e/ou negligência das figuras parentais e os rearranjos familiares caminham lado a lado com a idealização de uma família unida e feliz (Yunes et al., 2001; Tfouni; Moraes, 2003).

Devemos registrar ainda que, para parte daqueles em situação de rua, as instituições de acolhimento representam suas casas, suprindo, pelo menos em parte, os vínculos familiares já enfraquecidos, rompidos ou mesmo inexistentes. Crianças e adolescentes acolhidos constroem vínculos de solidariedade entre si, que surgem a partir de vivências cotidianas, mas, ainda assim, os conflitos e a desconfiança persistem (Medeiros et al., 2002). 


\section{Instituições de acolhimento}

De acordo com a literatura analisada, crianças e adolescentes em situação de rua recorrem às instituições de acolhimento para suprir suas necessidades básicas de alimentação, higiene, lazer, segurança, entre outras. O papel que esses espaços ocupam em suas vidas é considerado fundamental, muito embora dificuldades de adaptação, carências financeiras e problemas políticos sejam comumente relatados.

Entre os objetivos das instituições de acolhimento estão a reinserção social, a defesa dos direitos e o fornecimento de condições básicas de sobrevivência para crianças e adolescentes em situação de rua. Essas instituições podem ser ainda espaços privilegiados de acolhimento, escuta e respeito. A avaliação positiva de seu desempenho, no geral, está centrada nas conquistas cotidianas que, embora pequenas em relação aos objetivos propostos pelas instituições, confortam os profissionais que ali atuam (Santana et al., 2004). No geral, a compreensão de que o trabalho realizado nestas instituições é limitado pelo contexto social mais amplo de exclusão no qual se insere também se faz presente (Conceição e Sudbrack, 2004).

Identificamos uma série de problemas relacionados a estes espaços nas publicações pesquisadas, dentre eles: a insuficiência de recursos financeiros; as dificuldades de articulação com a rede de atendimento; as constantes mudanças nas propostas de trabalho; a rotatividade dos educadores sociais; as regras que parecem arbitrárias e inadequadas para parte dos adolescentes; o afastamento dos amigos e da família; a ociosidade; e a ausência de um atendimento individualizado (Moura; Silva; Noto, 2009; Nogueira e Bellini, 2006). Além disso, são comuns críticas relacionadas ao fato de que nessas instituições subsistem características de "instituição total", o que viola os direitos de crianças e adolescentes e dificulta seu processo de formação de identidade e autonomia (Ribeiro e Ciampone, 2002).

Sobre as perspectivas de futuro de crianças e adolescentes acolhidos após sua vivência em situação de rua, é possível observar desafios relacionados à alteração na noção temporal e espacial destes sujeitos e à desorganização das referências básicas de suas histórias de vida (Ferreira; Littig; Vescovi, 2014). Por outro lado, o despertar para novas perspectivas e para o processo de reinserção social é possível quando amparado por ações pedagógicas e pelo fortalecimento das relações entre as meninas e os educadores sociais inseridos nas instituições (Oliveira e Medeiros, 2006). 


\section{Violência}

O tema da violência é um dos mais recorrentes nas pesquisas que focalizam a população infantil e adolescente em situação de rua. Nestes casos, a violência reportada não é apenas física, mas também psíquica, emocional e simbólica. Muito embora, a compreensão de crianças, adolescentes e jovens em situação de rua sobre a violência seja pontual e da ordem do vivido, o fato é que ela repercute sobre a saúde física e mental destes sujeitos a curto e longo prazo e está associada a fatores sociais mais amplos como a desigualdade social e econômica (Carinhanha, 2009).

Para muitas crianças e adolescentes a violência começa a ser experimentada nos primeiros anos de vida, ainda no contexto familiar. A ida para as ruas torna-se uma busca por espaços de proteção, sendo o abandono, a negligência e o uso abusivo de álcool e outras drogas considerados as principais causas dessa modalidade de violência (Arpini; Quintana; Gonçalves, 2010).

Nas ruas, a situação não costuma ser diferente. A exposição à violência faz parte da dinâmica destes espaços e ela não é só derivada das precárias condições de vida, ela é também moral, em forma de xingamentos, por exemplo, e física, em formas que podem até mesmo levar à morte (Silva, 2005). Relatos de violência são bastante comuns e revelam que a rua vulnerabiliza e torna crianças e adolescentes vítimas potenciais de agressões físicas e verbais, exploração do próprio trabalho e exposição às drogas. Ataques de gangues rivais, abusos físicos e sexuais e humilhações pela polícia e pela sociedade de modo geral fazem parte do cotidiano daqueles que vivem em situação de rua e reforçam a estratégia de organização em grupo para proteção (Cirino e Alberto, 2009; Nogueira e Bellini, 2006; Rizzini e Neumann; Cisneros, 2009).

Um outro ponto a ser destacado é que, em alguns contextos, crianças e adolescentes em situação de rua podem também assumir o papel de vitimizadores (agressores), o que pode ser entendido como uma tentativa de romper com o papel de vítima (Paludo e Koller, 2005). O uso de drogas parece precipitar o envolvimento dos adolescentes em episódios de violência. Isso porque seu consumo provoca mudanças de comportamento que parecem encorajar e anestesiar os momentos em que eles cometem ou são vítimas de violência (Arpini e Gonçalves, 2011). Essa prática também complica a relação destes sujeitos com agentes da segurança pública, representados, principalmente, pela figura dos policiais. Estes costumam ser descritos como violentos, preconceituosos e agressivos, embora, em alguns casos, o caráter protetivo da ação policial seja reconhecido (Cerqueira-Santos et al., 2006; Moura; Silva; Noto, 2009). 


\section{Drogas}

O consumo de drogas é outra questão frequentemente abordada na produção acadêmico-cientifica sobre crianças e adolescentes em situação de rua. De modo geral, compreende-se que situações de vulnerabilidade, mesmo quando experimentadas ainda no ambiente familiar, contribuem para o uso precoce dessas substâncias. A ida para as ruas aprofunda condições de vida adversas, reforçando, em muitos casos, o uso de drogas como estratégia de sobrevivência. Além de amenizar a fome e a violência cotidiana, esta prática é uma forma de iniciação em grupos que são importantes facilitadores para a sobrevivência nas ruas.

Embora o uso de cola e de solventes tenha sido destacado em alguns dos estudos analisados, o consumo de crack parece despertar a preocupação de grande parte dos pesquisadores, sobretudo quando considerada sua relação com situações de empobrecimento social, com destaque para contextos de moradia precária e desabrigamento (Mota, 2012; Claro et al., 2014; Brandão, 2013; Nunes e Andrade, 2009).

A dinâmica familiar aparece como um elemento importante a ser observado no que tange esta questão, ora desempenhando papel protetor, ora facilitador, em relação ao uso de drogas (Neiva-Silva, 2008). A relação desta prática com os "comportamentos de risco", alguns vinculados à busca pela droga e outros ao estado de "intoxicação", também se destaca (Moura; Silva; Noto, 2009). Além disso, existem preocupações relacionadas ao fato de que as drogas proporcionam um prazer imediato, que pode diminuir outros interesses, fazendo com que as crianças e os adolescentes abandonem os estudos e o brincar, tornando preponderante a necessidade de conseguir dinheiro para sobreviver e sustentar o uso de drogas (Nunes e Andrade, 2009).

Nas análises realizadas, o consumo de drogas pela população em situação de rua também está relacionado à falta de estrutura e à desarticulação dos serviços públicos. Precárias condições em instituições do tipo casa de passagem revelam a negligência do poder público em relação a esta população e contribuem para ampliar a vulnerabilidade de crianças e adolescentes e os distanciar dos programas de saúde e assistência (Mota, 2012). O tratamento político e assistencial destinado a crianças e adolescentes em situação de rua usuários de drogas, baseado em práticas repressivas e na violência sancionada pelo estado, parece tornar essa prática ainda mais destrutiva e reforça o estigma em torno do consumo e dos usuários (Brandão, 2013; Nunes, 2013). 


\section{Trabalho infantil e adolescente}

Sabe-se que problemas econômicos e financeiros fazem parte do rol de elementos que afastam crianças e adolescentes de suas casas. Seja com o objetivo de contribuir para o sustento familiar, seja com o objetivo de conseguir bens para si mesmos, grande parte daqueles que chegam às ruas desempenham algum tipo de trabalho.

Entre os estudos analisados foi possível identificar que as famílias contribuem, direta ou indiretamente, no desenvolvimento das atividades e na mobilização de estratégias para a realização do trabalho infantil, cumprindo papéis diferentes na divisão de tarefas, no planejamento e desenvolvimento do trabalho. Ao mesmo tempo em que esta participação favorece as crianças, pois pode amenizar a carga física da atividade e contribuir para a formação de valores e normas para o trabalho, esse comportamento expressa a aceitação e a participação familiar e da sociedade na estruturação do trabalho infantil (Cruz e Assunção, 2008). Os riscos que permeiam o trabalho infantil, sobretudo no que tange à violência, a redução das perspectivas de estudo e os danos provocados ao desenvolvimento biopsicossocial de crianças e adolescentes fazem parte das preocupações notadas pelos pesquisadores. Crianças e adolescentes parecem compreender que perspectivas positivas de futuro estão associadas ao afastamento das drogas e ao retorno à escola, o que reforça o importante papel que pode ser exercido por essas instituições no enfrentamento ao trabalho precoce e a educação preventiva (Cirino e Alberto, 2009).

\section{Educação/Escola}

Embora a importância da educação e das oportunidades a ela associadas seja um tema frequentemente abordado nos estudos sobre crianças e adolescentes em situação de rua, observa-se uma grande lacuna no que se refere à análise acerca das condições de escolarização. Crianças e adolescentes em situação de rua compõem um grupo heterogêneo. Dessa forma, não podemos deixar de sinalizar que o caso daquelas que vivem em instituições de acolhimento ou que desempenham atividades laborais nas ruas, mas retornam para suas casas no final do dia, é diferente. Entre essas crianças, a ida à escola é mais comum, sobretudo quando obrigatória, se vinculada a programas governamentais de distribuição de renda.

De forma geral, considera-se que a falta de capital econômico, cultural e social prejudica o acesso à educação. Como estes fatores são fortemente atravessados por condições socioeconômicas, as famílias pobres, assim como as crianças e os adolescentes em situação de rua, vivenciam processos de 
vulnerabilização que limitam suas possibilidades de escolarização. Todavia, o acesso à educação pode ser influenciado, restringido ou ampliado, por um conjunto de fatores que vão além das dimensões estritamente econômicas, como o número de dias trabalhados, a moradia na rua, a idade, a gravidez precoce e a localização em determinados municípios da região metropolitana. Por outro lado, políticas públicas de transferência de renda, tais como o Bolsa Família e o Programa de Erradicação do Trabalho Infantil (Peti), parecem ampliar as possibilidades de estudo, mesmo entre segmentos mais vulneráveis (Ferreira; Nogueira Jr.; Costa, 2010).

Alguns estudos evidenciam a necessidade de mudanças para garantir o acesso e permanência de crianças e adolescentes em situação de rua em instituições educacionais. Eles indicam ser preciso alterar a organização, a estrutura e as relações das escolas de modo a criar mecanismos adequados para esse grupo populacional. A lógica de seriação, seletividade e avaliação, visando sempre o aluno médio, faz com que a escola não apareça como possibilidade para aqueles que vivem nas ruas, impedindo a garantia do seu direito à educação. As capacidades e habilidades desses adolescentes são ignoradas, mesmo que garantam a sua sobrevivência em contextos de extrema vulnerabilidade. O mesmo ocorre com sua história, cultura e linguagem (Silva, 2005). Além disso, as condições de desigualdade que marcam os estudantes que vivem em situação de rua, aí incluídos maus-tratos, discriminação e desrespeito, imprimem a ausência de reconhecimento social dessa população, que necessita da construção de estratégias capazes de mitigar os efeitos da desigualdade social para permanecer na escola. Entre as estratégias citadas estão: a possibilidade de acesso a consultas médicas, ao direito de ter documentos, de usar roupas limpas e de ser chamado pelo nome. Isso ajudaria a transformar as escolas em espaços de luta por reconhecimento social e pela emancipação através da educação (Godinho, 2015).

\section{Saúde}

Diversos estudos apontam que, nas ruas, crianças e adolescentes estão expostos a uma série de fatores de risco, tais como a ausência de um abrigo seguro, a difícil manutenção de hábitos de alimentação e higiene adequados, o trabalho infantil, o uso de drogas e a prática sexual como estratégia de sobrevivência. Esses elementos impactam diretamente em sua saúde e as consequências de viver na rua podem manifestar-se através de doenças, da dependência química, da má nutrição, da morte prematura, entre tantos outros (Morais et al., 2010). Os sentimentos de imunidade e onipotência, comuns na adolescência, podem contribuir para que eles se exponham ainda mais a riscos 
e a relações sexuais sem o uso de preservativos, aumentando significativamente suas chances de exposição às doenças sexualmente transmissíveis (DSTs) e a Aids. A falta de informações e a dificuldade de processá-las de maneira adequada, aliadas ao precário acesso aos serviços de saúde, contribuem para o agravamento deste cenário (Schwonke; Fonseca; Gomes, 2009).

Contudo, pesquisas também indicam que as ruas podem oferecer fatores de proteção e a saída de casa pode significar a tentativa de construção de uma "estratégia saudável" diante de ambientes familiares extremamente pobres e violentos. Analisar esses elementos pode contribuir para uma compreensão mais abrangente e realista do desenvolvimento humano (Morais, 2005; Lima, 2014). A má alimentação, por exemplo, que interfere diretamente nos processos de saúde-doença, faz parte do cotidiano de um grande número de famílias e isso acaba impulsionando parte das crianças e adolescentes para as ruas em busca de sustento para si e seus familiares (Medeiros; Freitas; Oliveira, 2004). Além disso, a ida para as ruas pode ser vista também como uma forma de escapar de fatores ambientais e psíquicos que causam danos físicos e psicológicos, mesmo que de forma inconsciente, conformando uma escolha criativa na busca por saúde mental (Botelho et al., 2008).

Sobre a promoção de saúde para crianças e adolescentes em situação de rua, alguns autores destacam que a construção de estratégias de atendimento em rede e em espaços que permitam a educação e a criação de novos vínculos parece ser a estratégia desejada, muito embora os desafios para o atendimento desta população ainda persistam. Exemplos disso são a dificuldade de acesso aos serviços pela ausência de um adulto responsável ou de um endereço fixo, a falta de rotina e as condições precárias em que vivem. Assim, alguns autores enfatizam a necessidade de adequação do atendimento ofertado a esta população (Oliveira e Ribeiro, 2006). Recomendações como a realização de escutas atenciosas e a valorização daqueles em situação de rua são indicadas como capazes de contribuir para a promoção de saúde, uma vez que permitem a identificação do contexto cultural dos participantes, facilitam o planejamento de métodos de intervenção adequados e despertam nos jovens o interesse de alertar seus pares sobre as questões abordadas (Luna, 2011).

\section{Considerações finais}

Embora a população em situação de rua seja um fenômeno histórico na sociedade brasileira, esse grupo só teve suas demandas específicas formalmente reconhecidas a partir do Decreto Federal n. 7053/2009, que instituiu a Política Nacional para a População em Situação de Rua. Embora o referido decreto tenha sido uma conquista fundamental e tenha impactado positivamente 
em dispositivos normativos e desenhos institucionais, sobretudo no campo da assistência social e da saúde, as especificidades da população infantil e adolescente não foram contempladas.

Frente a este desafio, um amplo movimento em defesa dos direitos de crianças e adolescentes vem atuando, sobretudo no âmbito do Conselho Nacional dos Direitos da Criança e do Adolescente (Conanda), com o objetivo de construir uma política nacional que contemple as especificidades de crianças e adolescentes em situação de rua. Articulados nacionalmente através da campanha “Criança não é de rua”, esse grupo, depois de muitas lutas e reveses, tornou-se o principal responsável pela publicação do documento Diretrizes nacionais para o atendimento a crianças e adolescentes em situação de rua, lançado em outubro de 2017 (Brasil, 2017). Esta publicação, que é resultado de um esforço coletivo de organizações da sociedade civil e de órgãos de governo, compila sessenta e quatro diretrizes que deverão orientar o trabalho de proteção social e promoção de direitos junto a este segmento.

Ao mesmo tempo em que acompanhamos avanços normativos fundamentais, constatamos também avanços nos debates e nos diversos estudos que versam sobre crianças e adolescentes em situação de rua. A maior parte dos estudos analisados neste artigo trazem questionamentos importantes às tipificações e às crenças que homogeneizavam este grupo, contribuindo para a compreensão dos arranjos culturais e históricos que caracterizam esses sujeitos. No entanto, ao retratar as crianças e adolescentes em situação de rua como sujeitos de direitos que se desenvolvem em contextos de extrema pobreza e vulnerabilidade, a produção analisada também reconhece a importância fundamental das políticas públicas para garantir a oferta de serviços específicos capazes de estimular o desenvolvimento das potencialidades de crianças e adolescentes em situação de rua, contribuindo para que eles alcancem seu desenvolvimento integral.

Apesar dos avanços existentes no campo normativo, nos debates públicos e na produção acadêmica sobre o tema em questão, ainda se observa o crescimento de práticas punitivas e repressivas que afetam diretamente aqueles que vivenciam contextos de pobreza e vulnerabilidade social. Sobre isso, destacam-se na agenda política atual os debates acerca da redução da maioridade penal, do aumento do tempo de internação para adolescentes no sistema socioeducativo, da permissão da divulgação de imagem de crianças e adolescentes em conflito com a lei e da redução da idade de trabalho para quatorze anos. Muito embora as análises aqui apresentadas sejam insuficientes para dar conta de uma questão tão complexa e desafiadora, elas revelam 
debates e preocupações recentes que são especialmente relevantes diante dos retrocessos no campo dos direitos humanos e dos múltiplos desafios de governabilidade que se apresentam.

Neste sentido, consideramos fundamental acrescentar algumas recomendações para políticas públicas voltadas para crianças e adolescentes em situação de rua identificadas nas pesquisas analisadas. Essas recomendações expressam a complexidade do tema abordado, ao mesmo tempo em que nos ajudam a compreender os desafios do cenário atual.

Diante das particularidades e complexidades da situação de rua, destaca-se a necessidade de maior articulação em rede e do desenvolvimento de um trabalho intersetorial e interdisciplinar capaz de assegurar a promoção e a proteção integral de crianças e adolescentes que vivenciam esta realidade. A ampliação do orçamento público destinado a essas ações, assim como uma maior participação da sociedade civil organizada neste debate, são elementos necessários para a oferta de serviços adequados a essa população. Além disso, recomenda-se a produção de dados e de estudos voltados para a compreensão do fenômeno e para o aprimoramento da ação dos órgãos públicos, tanto no que se refere à elaboração, quanto à implementação e o monitoramento das políticas públicas.

As recomendações também se voltam para os profissionais envolvidos no atendimento a crianças e adolescentes em situação de rua. A importância do cuidado e da escuta, da contínua formação pessoal e capacitação profissional e da criação de espaços de discussão e supervisão sistemáticas são alguns elementos apontados como capazes de transformar as situações de trabalho e aprimorar o atendimento ofertado.

Outra questão que merece destaque é a importância da participação de crianças, adolescentes e jovens na construção e execução de propostas referentes ao seu atendimento. Neste sentido, é necessário criar espaços de participação e decisão através dos quais esses sujeitos possam expressar suas demandas e se tornar agentes nas decisões que versam sobre suas vidas. Iniciativas que oportunizam o exercício da cidadania, assim como a reinserção social e a construção de projetos de vida são fundamentais.

Por fim, destaca-se a importância do investimento nas famílias e comunidades de origem de crianças e adolescentes em situação de rua, como uma estratégia de fortalecer suas bases de apoio nestes contextos. As violações de direitos permanecem frequentes entre estes sujeitos que transitam entre a casa, as ruas e as diferentes instituições de acolhimento e/ou privação de liberdade. Assim, torna-se fundamental a busca pela formulação, pela implementação e pelo monitoramento de políticas públicas efetivas, capazes 
de assegurar que crianças e adolescentes em situação de rua recebam proteção do estado e adquiram visibilidade na agenda política do país.

\section{Referências}

ALVES, Paola; KOLLER, Silvia; SILVA, Aline; SANTOS, Clarisse; SILVA, Milena; REPPOLD, Caroline; PRADE, Luciano. Atividades cotidianas de crianças em situação de rua. Psicologia: teoria e pesquisa, v. 18, n. 3, p. 305-313, $2002<10.1590 /$ S010237722002000300010>.

ARPINI, Dorian; GONÇALVES, Camila. Drogas e álcool na relação com a violência: o olhar de adolescentes em situação de rua. Psico, v. 42, n. 4, p. 442-449, 2011.

ARPINI, Dorian; QUINTANA, Alberto; GONÇALVES, Camila. Relações familiares e violência em adolescentes em situação de rua. Psicologia Argumento, v. 28, n. 63, p. 325-336, 2010.

BOTELHO, Adriana; SILVA, Samantha; KASSAB, Marina; LEITE, Ligia. Meninos de rua: desafiliados em busca de saúde mental. Psicologia em Estudo, v. 13, n. 2, p. 361-370, 2008.

BRANDÃO, Beatriz. O Estado nas margens e as margens do Estado: ações políticas para meninos em condição de rua usuários de crack. Publicatio UEPG, v. 21, n. 2, p. $173-180,2013<10.5212 /$ PublicatioCi.Soc.v.21i2.0004>.

BRASIL. Diretrizes nacionais para o atendimento a crianças e adolescentes em situação de rua. Brasília: Conanda; SNDCA/MDH; CNER, 2017 < primeirainfancia. org.br/wp-content/uploads/2017/08/0344c7_4fe2ba1cd6854b649d45d71a6517f80d. pdf> (26 dez. 2018).

CARINHANHA, Joana. Violência vivenciada pelas adolescentes em situação de rua: bases para o cuidado de enfermagem pela cidadania. Rio de Janeiro: UerJ, 2009. Dissertação de mestrado em Enfermagem.

CERQUEIRA-SANTOS, Elder; KOLLER, Silvia; PILZ, Christian; DIAS, Daniela; WAGNER, Flávia. Concepções de policiais sobre crianças em situação de rua: um estudo sobre preconceito. PsicoUSF, v. 11, n. 2, p. 249-256, $2006<10.1590 /$ S1413$82712006000200013>$.

CIRINO, Daniele; ALBERTO, Maria de Fátima. Uso de drogas entre trabalhadores precoces na atividade de malabares. Psicologia em Estudo, v. 14, n. 3, p. 547-555, 2009.

CLARO, Heloísa. OLIVEIRA, Maria Aparecida; RIBEIRO, Anna Paula; FERNANDES, Caty; CRUZ, Alexandre; SANTOS, Eva. Perfil e padrão de uso de crack de crianças e adolescentes em situação de rua: uma revisão integrativa. SmadRevista eletrônica saúde mental, álcool e drogas. v. 10, n. 1, p. 35-41, $2014<10.11606 /$ issn.1806-6976.v10i1p35-41>.

CONCEIÇÃO, Maria Inês; SUDBRACK, Maria Fátima O. Estudo sociométrico de uma instituição alternativa para crianças e adolescentes em situação de rua: construindo uma proposta pedagógica. Psicologia: reflexão e crítica, v. 17, n. 2, p. 277-286, 2004 $<10.1590 /$ S0102-79722004000200015>. 
CRUZ, Maria Núbia; ASSUNÇÃO, Ada. Estrutura e organização do trabalho infantil em situação de rua em Belo Horizonte, MG, Brasil. Saúde e Sociedade, v. 17, n. 1, p. 131-142, $2008<10.1590 /$ S0104-12902008000100012>.

ESTIVALET, Anelise. Os sem-lugar: uma análise de trajetórias de jovens que vivem nas ruas de Porto Alegre. Revista EGP, 2010.

FERREIRA, Frederico; NOGUEIRA JR., Reginaldo; COSTA, Bruno. Determinantes da escolarização de crianças e adolescentes em situação de rua no estado de Minas Gerais. Ensaio: avaliação e políticas públicas em educação, v. 18, n. 68, p. 465-488, $2010<10.1590 /$ S0104-40362010000300004>.

FERREIRA, Vanda; LITTIG, Patrícia; VESCOVI, Renata. Crianças e adolescentes abrigados: perspectiva de futuro após situação de rua. Psicologia \& Sociedade, v. 26, p.165-174, $2014<10.1590 /$ S0102-71822014000100018>.

GODINHO, Josiane. A escola de quem não tem escola: os desafios da escolarização para jovens em situação de rua. Porto Alegre: Pucrs, 2015. Dissertação de mestrado em Educação.

LEAL, Eduardo Martinelli. "Da porta para fora": a constituição de um problema social. Ponto Urbe, 1, p. 1-27, $2007<10.4000$ /pontourbe.1217>.

LIMA, Rebeca. Bem-estar subjetivo de crianças e adolescentes em situação de rua. Fortaleza: Unifor, 2014. Dissertação de mestrado em Psicologia.

LUNA, Izaildo. Educação em saúde com adolescentes em situação de rua visando à prevenção de DST/Aids. Fortaleza: UFC, 2011. Dissertação de mestrado em Enfermagem.

MATIAS, Hugo. Jovens em situação de rua: espaço, tempo, negociações de sentido. Psicologia \& Sociedade, v. 23, n. 2, p. 237-247, $2011<10.1590 /$ S010271822011000200004>.

MARTINS, Raul. Uma tipologia de crianças e adolescentes em situação de rua baseada na Análise de Aglomerados. Psicologia: reflexão e crítica, v. 15, n. 2, p. 251-260, 2002 $<10.1590 /$ S0102-79722002000200003>.

MEDEIROS, Marcelo; FERRIANI, Maria das Graças; GOMES, Romeu; MUNARI, Denize. O significado de casa e rua para meninos com experiência de vida nas ruas: em busca de uma compreensão sobre as implicações para a saúde. Revista Brasileira do Crescimento e Desenvolvimento Humano, v. 12, n. 2, p. 11-19, 2002.

MEDEIROS, Marcelo; FREITAS, Geovana; OLIVEIRA, Normalene. A fome para meninos e meninas em situação de rua: além da sensação da "barriga vazia". Revista Brasileira do Crescimento e Desenvolvimento Humano, v. 14, n. 1, $2004<10.7322$ / jhgd.39788>.

MORAIS, Normanda. Um estudo sobre a saúde de adolescentes em situação de rua: o ponto de vista de adolescentes, profissionais de saúde e educadores. Porto Alegre: Ufrgs, 2005. Dissertação de mestrado em Psicologia.

MORAIS, Normanda; MORAIS, Camila; REIS, Silvia; KOLLER, Silvia. Promoção de saúde e adolescência: um exemplo de intervenção com adolescentes em situação de rua. Psicologia \& Sociedade, v. 22, n. 3, p. 507-518, $2010<10.1590 /$ S0102$71822010000300011>$. 
MOTA, Rubens. A trajetória de jovens em situação de rua usuários de crack. Brasília: UCB, 2012. Dissertação de mestrado em Psicologia.

MOURA, Yone; SILVA, Eroy; NOTO, Ana. Redes sociais no contexto de uso de drogas entre crianças e adolescentes em situação de rua. Psicologia em Pesquisa, v. 3, n. 1, p. 31-46, 2009.

NEIVA-SILVA, Lucas. Uso de drogas entre crianças e adolescentes em situação de rua: um estudo longitudinal. Porto Alegre: Ufrgs, 2008. Tese de doutorado em Psicologia, 2008.

NÓBREGA, Sheva; LUCENA, Taciana. O "menino de rua" entre o sombrio e a aberrância da exclusão social. Estudos de Psicologia, v. 21, n. 3, p. 161-172, 2004 $<10.1590 /$ S0103-166X2004000300002>.

NOGUEIRA, Luciana; BELLINI, Luzia Marta. Sexualidade e violência, o que é isso para jovens que vivem na rua? Texto Contexto Enfermagem, v. 15, n. 4, p. 610-616, $2006<10.1590 /$ S0104-07072006000400009>.

NUNES, Eliane; ANDRADE, Arthur. Adolescentes em situação de rua: prostituição, drogas e HIV/AIDS em Santo André. Psicologia \& Sociedade, v. 21, n. 1, p. 45-54, $2009<10.1590 /$ S0102-71822009000100006>.

NUNES, Rosane. Concepções de tratamento de crianças e adolescentes usuários de drogas com experiência de vida nas ruas no município do Rio de Janeiro. Rio de Janeiro: PUC Rio, 2013. Dissertação de mestrado em Serviço Social.

OLIVEIRA, Alfredo; RIBEIRO, Moneda. O cuidar da criança de/na rua na perspectiva dos graduandos de enfermagem. Texto \& Contexto Enfermagem, v. 15, n. 2, p. 246-53, $2006<10.1590 /$ S0104-07072006000200008>.

OLIVEIRA, Normalene; MEDEIROS, Marcelo. Histórias de vida de meninas com experiência pregressa nas ruas: perspectivas do processo de inclusão social. Revista Eletrônica de Enfermagem, v. 8, n. 1, p. 119-127, $2006<10.5216 /$ ree. v8i1.935>.

PALUDO, Simone; KOLLER, Silvia. Quem são as crianças que estão nas ruas: vítimas ou vitimizadoras? Interação em Psicologia, v. 9, n. 1, p. 65-76, $2005<10.5380 /$ psi. v9i1.3287>.

PALUDO, Simone; KOLLER, Silvia. Toda criança tem família: criança em situação de rua também. Psicologia \& Sociedade, v. 20, n. 1, p. 42-52, $2008<10.1590 /$ S010271822008000100005>.

RIBEIRO, Moneda. A criança de/na rua tem família: uma família em crise. Revista Brasileira de Crescimento e Desenvolvimento Humano, v. 11, n. 1, $2001<10.7322$ / jhgd.39667>.

RIBEIRO, Moneda; CIAMPONE, Maria Helena. Crianças em situação de rua falam sobre os abrigos. Revista da Escola de Enfermagem da USP, v. 36, n. 4, p. 309-316, $2002<10.1590 /$ S0080-62342002000400003>.

RIZZINI, Irene; NEUMANN, Menezes; CISNEROS, Arianna. Estudos contemporâneos sobre a infância e paradigmas de direitos. O Social em Questão, n. 21, p. 1-13, 2009. 
SANTANA, Juliana; DONINELLI, Thaís; FROSI, Raquel; KOLLER, Sílvia. Instituições de atendimento a crianças e adolescentes em situação de rua. Psicologia \& Sociedade, v. 16, n. 2, p. 59-70, $2004<10.1590 /$ S0102-71822004000200008>.

SCHWONKE, Camila; FONSECA, Adriana; GOMES, Vera Lucia. Vulnerabilidades de adolescentes com vivências de rua. Escola Anna Nery, v. 13, n. 4, p. 849-55, 2009 $<10.1590 /$ S1414-81452009000400022>.

SILVA, Josianne; AVELAR, Telma. Crianças em situação de rua e suas representações sobre lar e família por meio do desenho. Psicologia Argumento, v. 32, n. 76, p. 69-77, 2014.

SILVA, Solange. A escola e a rua: interação possível? Revista de Ciências Humanas, n. 37 , p. $67-87,2005$.

SOBRAL, Maria. Trajetórias de vida: um estudo sobre a complexidade da experiência na rua. 2008. 160f. Dissertação - PPG em Psicologia, UFP, Pernambuco, 2008.

TFOUNI, Leda; MORAES, Juliana. A família narrada por crianças e adolescentes de rua: a ficção como suporte do desejo. Psicologia USP, v. 14, n. 1, 2003.

WINNICOTT, Donald. Tudo começa em casa. São Paulo: Martins Fontes, 1996.

YUNES, Maria Ângela; ARRIECHE, Maria Rosaura; TAVARES, Maria de Fátima; FARIA, Lucimeri. Família vivida e pensada na percepção de crianças em situação de rua. Paidéia, v. 11, n. 20, p. 47-56, 2001.

Recebido: 29 maio 2018

Aceito: 26 nov. 2018

Publicado: 01 mar. 2019

Autora correspondente:

Irene Rizzini

PUC-Rio, Departamento de Serviço Social

Rua Marquês de São Vicente, 225 - Gávea

22453-900 Rio de Janeiro, RJ, Brasil

IRENE RIZZINI <irizzini.pucrio.ciespi@gmail.com>

Doutora em Sociologia pelo Instituto Universitário de Pesquisas do Rio de Janeiro (Rio de Janeiro, Brasil), professora na Pontifícia Universidade Católica do Rio de Janeiro (Puc-Rio, Rio de Janeiro, RJ, Brasil).

Orcid: http://orcid.org/0000-0002-1154-7998

RENATA MENA BRASIL Do COUTO <renatabr83@gmail.com>

Doutora em Serviço Social pela Universidade Federal do Rio de Janeiro (Rio de Janeiro, Brasil), pesquisadora do Centro Internacional de Estudos e Pesquisas sobre infância (Ciespi/Puc-Rio, Rio de Janeiro, RJ, Brasil).

Orcid: http://orcid.org/0000-0003-2030-0636 